\title{
Aplicação dos pilares da indústria 4.0 na educação
}

\section{Application of industry 4.0 pillars in the education}

\author{
1 Márcia Gorett Ribeiro Grossi marciagrossi@terra.com.br http://orcid.org/0000-0002-3550-6680 \\ 2 Thiago Fiuza de Sousa Cruz http://orcid.org/0000-0002-4094-8758 \\ 3 Dalva de Souza Minoda http://orcid.org/0000-0002-4679-8172 \\ 4 Natália Trindade de Souza http://orcid.org/0000-0003-2461-6996
}

\footnotetext{
Doutora em Ciência da Informação pela UFMG. CEFET-MG

Mestre em Educação Tecnológica pelo CEFET-MG.

Mestranda em Educação Tecnológica pelo CEFET-MG.

4 Mestre em Educação Tecnológica pelo CEFET-MG.
}

\section{Resumo}

A educação está vivenciando o início do seu $4^{\circ}$ período, evidenciando-se uma evolução de suas práticas pedagógicas e passando por mudanças significativas, o que fez surgir a questão que inspirou esta pesquisa: é possível utilizar os avanços tecnológicos da indústria 4.0 no contexto escolar para efetivar o modelo educacional 4.0? Para responder a essa questão, o objetivo desse artigo foi verificar as possibilidades de se usar os nove pilares da indústria 4.0, estabelecidos pelo Boston Consulting Group, no contexto escolar, de forma a contribuir para a efetivação do modelo da educação 4.0. Par tal, foi realizada, em 2021, uma pesquisa de abordagem qualitativa. De acordo com o objetivo traçado, o tipo de pesquisa foi descritiva e, em relação aos procedimentos técnicos, escolheu-se a pesquisa bibliográfica. Os resultados revelaram que esses pilares da indústria podem ser aplicados na educação, ajudando na efetivação da educação 4.0. 0 uso desses pilares pôde ser observado diretamente nas práticas pedagógicas, como favorecimento das metodologias ativas, destacando, nesta pesquisa, a aprendizagem baseada em projetos, a sala de aula invertida, o design thinking e atividades maker. E, também, indiretamente, como ferramenta de apoio na gestão escolar como, por exemplo a computação em nuvem, que elimina a necessidade de instalação de softwares ou sistemas nos computadores locais da escola, reduzindo a necessidade de altos investimentos financeiros em armazenagem de dados escolares.

\section{Palavras-chave:}

Educação 4.0. Pilares da indústria 4.0. Práticas pedagógicas.

\section{Como você deve citar?}

GROSSI, Márcia Gorett Ribeiro et al. Aplicação dos pilares da indústria 4.0 na educação. Cadernos UniFOA, Volta Redonda (RJ), v. 16, n. 47, p. 63 - 74, dez, 2021.

\begin{abstract}
The education is experiencing the beginning of its 4th period, showing an evolution of its pedagogical practices and undergoing significant changes, which raised the question that inspired this research: is it possible to use the technological advances of industry 4.0 in the school context to implement the 4.0 educational model? To answer this question, the objective of this article was to verify the possibilities of using the pillars of industry 4.0, established by the Boston Consulting Group, in the school context, contributing to the effectiveness of the 4.0 education model. To this end, a qualitative research was carried out in 2021. According to the outlined objective, the type of research was descriptive, and in relation to technical procedures, bibliographic research was chosen. The results revealed that these pillars of the industry can be applied in education, helping to make education 4.0 effective. The use of these pillars could be observed directly in pedagogical practices, as favoring active methodologies, highlighting in this research: projectbased learning, the inverted classroom, design thinking and maker activities. And also, indirectly, as a support tool in school management such as, for example, cloud computing that eliminates the need to install software or systems on local school computers, reducing the need for high financial investments in storing school data.
\end{abstract}

\section{Keywords:}

Education 4.0. Pillars of industry 4.0. Pedagogical practices. 


\section{INTRODUÇÃO}

A educação é um "processo de toda a sociedade - não só da escola - que afeta a todas as pessoas, o tempo todo, em qualquer situação pessoal, social, profissional e através de todas as formas possíveis" (MORAN, 2007, p.14), e, ao mesmo tempo, as mudanças sociais também influenciam a área da educação.

Assim, ao longo do tempo, a educação tem se modificado, de forma que as práticas pedagógicas, os papéis dos professores e dos alunos, a interação entre eles e o espaço onde ela ocorre têm sido influenciados pelas organizações sociais, principalmente no que diz respeito aos avanços tecnológicos. À vista disso, a história da educação desenrolou-se por três períodos e, atualmente, vivencia-se o início do $4^{\circ}$ período, evidenciando-se, portanto, uma evolução dos modelos educacionais de acordo com cada um desses períodos.

O primeiro modelo, o qual Lengel (2017) denomina educação 1.0, ocorreu no final do século XVIII. Era uma época de predominância da agricultura e do serviço manufatureiro. 0 período de vigência desse modelo teve como principal característica o ensino individual com o foco no professor, responsável por todas as disciplinas. As escolas eram chamadas de Escolas Paroquiais, pois as aulas aconteciam, geralmente, em igrejas ou paróquias e, o ensino era limitado às lições das escrituras e à leitura e estudos dos salmos (FRANCO, 2014).

Por volta do século XIX, com a $1^{\text {a }}$ revolução industrial, iniciou-se a substituição das máquinas a vapor pelas máquinas elétricas e o local de trabalho passou a ser a fábrica e, consequentemente, 0 ambiente educacional foi alterado, surgindo a educação 2.0, na qual a sala de aula assumia os moldes da indústria, tornando a educação mecanizada e o ensino padronizado. 0 ritmo de aprendizagem era determinado pelo tempo cartesiano e quantificado, expresso pelo relógio, pelo sinal (o mesmo dos turnos das fábricas) e, o conhecimento era fragmentado por disciplinas (SILVA; CAMARGO, 2015). 0 ensino tinha ênfase na memorização dos conteúdos e as tecnologias começaram a ser adotadas cautelosamente, surgindo os imigrantes digitais.

Com a revolução tecnológica, ocorrida nos meados do século $X X$, iniciou-se a mudança da era industrial para a pós-industrial. Durante esse período, observou-se o desenvolvimento da eletrônica, da automação e de novas tecnologias digitais em um novo cenário socioeconômico mundial. A sociedade mudou e passou a ser chamada, por Castells (1999), de sociedade em rede, surgindo a era digital (SCHMIDT; COHEN, 2013), dando início a mais uma mudança na educação, a educação 3.0. 0 aluno nascido nesse período era chamado de nativo digital, pertencente à geração internet (TAPSCOTT, 2010).

Nesse período, os alunos começaram assumir o centro do processo de ensino-aprendizagem, atuando de maneira engajada e ativa. O papel do professor foi alterado e ele passou a ter a função de orientador do aluno, ajudando-o a compreender como ele aprendia. Além disso, as tecnologias passaram a estar cada vez mais presentes nas práticas pedagógicas (FRANCO, 2014).

Já no século XXI, os avanços tecnológicos estão mais latentes e possibilitam a $4^{\mathrm{a}}$ revolução industrial ou indústria 4.0, tendo, como principal característica, a junção de tecnologias digitais, automatizadas, autônomas e com possibilidade de integração biológica, aumentando a produção de maneira exponencial, suportada por nove pilares, de acordo com o Boston Consulting Group: Big Data; robôs autônomos; simulação; integração de sistemas; internet das coisas (IoT); cibersegurança; computação em nuvem; manufatura aditiva e a realidade aumentada (LAVAGNOLI, 2018).

Nesse período, o modelo educacional é chamado de 4.0, caracterizado pelas tecnologias com a capacidade de customizar a experiência de aprendizagem (LAVAGNOLI, 2018). Mais uma vez, os papéis 
dos alunos e professores mudam. Os alunos são guiados pelos seus interesses particulares, atraídos por temas pelos quais tenham afinidade, de forma a ampliar também o currículo definido pela escola (ANDRADE, 2018). Do lado dos professores, reforça-se as funções de mediadores e orientadores dos alunos no processo de ensino-aprendizagem, o qual é permeado por novas práticas pedagógicas, como as metodologias ativas e o ensino personalizado.

A partir desse contexto e lembrando que ensinar é um processo complexo que exige mudanças significativas (MORAN, 2004), surge a questão que inspirou esta pesquisa: é possível utilizar os avanços tecnológicos da indústria 4.0 no contexto escolar para efetivar o modelo educacional 4.0 ?

Para responder a essa questão, o objetivo deste artigo foi verificar as possibilidades de se usar os nove pilares da indústria 4.0, estabelecidos pelo Boston Consulting Group, no contexto escolar, de forma a contribuir para a efetivação do modelo da educação 4.0.

A justificativa para a realização desta pesquisa é o fato de que as instituições de ensino que buscam o modelo da educação 4.0 não podem desconsiderar as inovações da indústria 4.0 nos seus processos de ensino-aprendizagem. A inovação no âmbito educacional também deve estar presente nas transformações da organização escolar. Porém, como levar essas inovações da indústria para a prática docente? Pretende-se demonstrar isso com exemplos reais. Logo, espera-se que ela desperte o interesse por parte de profissionais da educação na aplicação dos noves pilares da indústria 4.0 na educação. Para tanto, este artigo fornece subsídio de como é possível aplicar cada um desses pilares diretamente como prática pedagógica, como também na gestão escolar.

\section{REFERENCIAL TEÓRICO}

\subsection{A influência da indústria 4.0 na sociedade}

Autores como Franco (2014), Lengel (2017), Lavagnoli (2018) e Carvalho (2019) mostram que as transformações industriais, ao longo dos anos, trouxeram muitas mudanças para a sociedade, o que justifica serem chamadas de Revolução. Os avanços tecnológicos implementados na indústria, já na $1^{\circ}$ Revolução, extrapolam os muros dos processos fabris, alterando a forma de viver, de se relacionar e de se comunicar. Assim, aconteceram também a $2^{\mathrm{a}}$ e $3^{\mathrm{a}}$ revoluções industriais, não sendo diferente no momento atual, em que se vive a $4^{a}$ revolução industrial.

Atualmente, a sociedade está na era digital, desenvolvendo em si uma cibercultura em que se evidencia uma transposição das culturas humanas para um espaço conectado, chamado de ciberespaço (LÉVY, 2009), o qual é construído sob tecnologias digitais e a internet em um movimento universal.

Consequentemente, a digitalização trouxe consigo alterações na forma como a sociedade lida com questões de espaço e tempo, propiciando mudanças profundas, caracterizadas pelo acúmulo cada vez maior e mais rápido de troca e armazenamento de dados no ciberespaço, somada à constante evolução tecnológica digital, afetando áreas como da saúde, da educação, do direito, das telecomunicações, dos transportes, da logística, do agronegócio, de serviços, entre outras. Para Antonio et al. (2018), nesse contexto, novos modelos de negócios acabam por surgir, tais como o

Uber que é a maior empresa de táxis sem possuir um carro, o Facebook que é a maior empresa de mídia e não produz um conteúdo sequer, a Ali Express não possui nenhum produto em seu estoque e detém o título de maior rede varejista e a Airbnb, que sem possuir nenhuma propriedade é a maior empresa de hospedagem do mundo (ANTONIO et al., 2018, p.11). 
Destarte, para as empresas brasileiras, em geral, a digitalização foi acelerada devido à pandemia de Coronavírus, iniciada no ano de 2019. De acordo com o Fórum Econômico Mundial, no Brasil, 92\% das empresas pesquisadas para o relatório The Future of Job perceberam uma aceleração da digitalização dos processos de trabalho, com o uso de ferramentas digitais, como, por exemplo, para realização de web conferências, enquanto $97 \%$ delas adotaram recursos da computação em nuvem - Cloud Computing (WORLD ECONOMIC FORUM, 2020, p. 71).

Dessa maneira, a digitalização da sociedade traz modelos de negócio influenciados pela nova relação empresa-consumidores. Esses modelos apresentam "novas formas de interações humanas e o consumo" (ROCHA et al., 2020, p. 9), transformando o modo de criação de produtos e, por consequência, a relação desses produtos com as pessoas. São produtos sustentáveis, fabricados em escala industrial, porém, são produtos customizados pelos consumidores, criados a partir de uma demanda específica, possibilitando a diminuição do excedente de produtos e desperdícios.

Em decorrência dessas mudanças realizadas no processo fabril e com a inserção das tecnologias pilares da indústria 4.0, foram desencadeados novos estudos, principalmente sobre o impacto do uso dessas tecnologias para os profissionais industriais. No relatório de 2018, o Fórum Econômico Mundial afirmou que, nos próximos cinco anos, a divisão do trabalho entre trabalhadores e máquinas trará mudanças nas competências necessárias ao trabalhador, consideradas como essenciais nos dias atuais, na ordem de 42\% (WORLD ECONOMIC FORUM, 2018, p. 24) pois, ao mesmo tempo em que profissões que possuam tarefas repetitivas serão substituídas pela automação e pelos algoritmos computacionais, surgirão novas profissões e atribuições relacionadas ao uso de tecnologia (WORLD ECONOMIC FORUM, 2018, p. 10).

Em 2020, as empresas brasileiras elegeram as capacidades de liderança, a influência social, o pensamento analítico e inovador, a aprendizagem ativa e a capacidade de usar estratégias de aprendizagem, como as principais competências que são o foco de programas de requalificação profissional (WORLD ECONOMIC FORUM, 2020, p. 72).

Para o World Bank Group (2019), a mudança das competências requeridas no processo industrial caminha para o aumento da "demanda por habilidades cognitivas avançadas, habilidades sociocomportamentais e combinações de habilidades associadas a uma maior adaptabilidade" (WORLD BANK GROUP, 2019, p. 5. Tradução nossa). Destaca-se que não se trata só do surgimento de novas profissões, mas, principalmente, da mudança de competências nos antigos postos de trabalho.

É observado também que a automação e a digitalização extrapolam as fábricas e chegam nas residências das pessoas, contribuindo com tarefas simples e na qualidade de vida, principalmente, com a expansão da Internet das Coisas, que são aplicadas às TVs, geladeiras, ar condicionado, relógios, fechaduras, câmeras de segurança, carros, entre outros dispositivos. Para Rocha et al. (2020, p. 10), "não se trata de ter mais dispositivos para acessar a internet, mas sim de hiperconectividade, ajudando a melhorar o uso dos objetos".

Esses autores, acerca da 4 a revolução, afırmam que "eis que, ao invés de competir com ela, é entender como ela funciona e tirar proveito das possibilidades que ela possa proporcionar para a resolução dos problemas da sociedade" (ROCHA et al., 2010, p. 11). Portanto, é inegável que essas mudanças já começaram e que as tecnologias pilares da indústria 4.0 já são uma realidade em vários contextos e não só na indústria.

Nessa perspectiva, percebe-se que surgem influências significativas na necessidade de adaptação do ambiente de produção e também na Educação. Como ajudar os alunos que estão na escola se 
estruturando em um projeto de vida, para integrarem uma sociedade na qual ainda não se sabe quais profissões existirão em médio prazo?

Não há dúvidas que há necessidade emergente no direcionamento para a formação de indivíduos criativos, inventivos, capazes de resolver problemas cada vez mais complexos, que não tenham restrições em trabalhar e se comunicar com as máquinas ou ainda que estejam habituados a resolver problemas enquanto lidam com conceitos inerentes à robótica, análise de dados, programação, redes, ao mesmo tempo em que conseguem operar novos equipamentos e dispositivos que surgirão a todo o momento.

O Boston Consulting Group estabeleceu nove pilares (Quadro 1) que se caracterizam como blocos na construção da indústria 4.0, com potencial de beneficiar técnica e economicamente os envolvidos na indústria e na sociedade em geral.

Quadro 1- Pilares da indústria 4.0

\begin{tabular}{|c|c|c|}
\hline Pilar & Descrição & Característica \\
\hline & $\begin{array}{l}\text { É um termo da Tecnologia da Informação } \\
\text { (TI) que trata da coleta, organização } \\
\text { e análise de enormes quantidades de } \\
\text { dados de fontes diversas. }\end{array}$ & $\begin{array}{l}\text { Otimiza a qualidade da produção, uma vez } \\
\text { que a análise dos dados pode correlacionar } \\
\text { etapas dos processos fabris com problemas } \\
\text { encontrados no produto acabado, permitindo a } \\
\text { tomada de decisão em tempo real. Possibilita } \\
\text { ainda a aplicação da Manutenção Preditiva } \\
\text { e Preventiva antecipando problemas no } \\
\text { processo industrial. }\end{array}$ \\
\hline & $\begin{array}{l}\text { É um termo que denomina os } \\
\text { procedimentos que objetivam a } \\
\text { segurança digital. }\end{array}$ & $\begin{array}{l}\text { Protege os dados e sistemas das ameaças } \\
\text { cibernéticas. }\end{array}$ \\
\hline & $\begin{array}{l}\text { É um termo associado ao fornecimento } \\
\text { de serviços de computação, tais como: } \\
\text { armazenamento de dados, bancos de } \\
\text { dados, rede, análise e inteligência, pela } \\
\text { Internet e sem o gerenciamento ativo } \\
\text { direto do utilizador. }\end{array}$ & $\begin{array}{l}\text { Permite uma maior quantidade de dados } \\
\text { passíveis de integração e economia de } \\
\text { hardware para as organizações, fazendo com } \\
\text { que os sistemas fiquem mais rápidos e dados } \\
\text { mais seguros, com redução de investimentos. }\end{array}$ \\
\hline & $\begin{array}{l}\text { É um termo que se refere a sistemas } \\
\text { de TI consistentes e interligados dentro } \\
\text { das empresas, como nos casos da } \\
\text { engenharia, da produção, de serviços } \\
\text { e, fora delas como as empresas, } \\
\text { fornecedores, distribuidores e clientes. }\end{array}$ & $\begin{array}{l}\text { Otimiza os processos e recursos, aumenta a } \\
\text { produtividade e diminui perdas. }\end{array}$ \\
\hline & $\begin{array}{l}\text { É um conceito que envolve a capacidade } \\
\text { de conexão digital de objetos físicos } \\
\text { com a internet, formando uma rede de } \\
\text { dispositivos conectados, capaz de reunir } \\
\text { e de transmitir dados. }\end{array}$ & $\begin{array}{l}\text { Possibilita, por exemplo, a automatização } \\
\text { dos processos, aumento da capacidade de } \\
\text { tomada de decisão em tempo real de forma } \\
\text { descentralizada. }\end{array}$ \\
\hline & $\begin{array}{l}\text { É também chamada de impressão 3D, } \\
\text { usada para a produção de protótipos } \\
\text { físicos e peças únicas. Os processos } \\
\text { de Manufatura aditiva apresentam um } \\
\text { fluxo de dados que criam instruções para } \\
\text { determinada prática, acompanhado por } \\
\text { um fluxo de trabalho físico, modificando } \\
\text { as matérias primas em produtos finais } \\
\text { (CARVALHO, 2019). }\end{array}$ & $\begin{array}{l}\text { Viabiliza a utilização em larga escala para } \\
\text { a produção de pequenos lotes de peças } \\
\text { customizadas, o que diminui o custo unitário } \\
\text { das peças, aumentando a velocidade da } \\
\text { produção, devido à prototipagem rápida. } \\
\text { Permite também testes e simulações de peças, } \\
\text { reduzindo perdas e refugos de produção. }\end{array}$ \\
\hline
\end{tabular}




\begin{tabular}{|l|l|l|}
\hline & $\begin{array}{l}\text { São robôs que podem executar tarefas } \\
\text { sem a supervisão humana, agindo de } \\
\text { forma inteligente, cooperativa e autônoma. }\end{array}$ & $\begin{array}{l}\text { Facilita a redução de custos com mão-de-obra } \\
\text { e aumenta a produção, tornando as indústrias } \\
\text { mais competitivas. }\end{array}$ \\
\hline $\begin{array}{l}\text { Em uma tecnologia que permite a } \\
\text { integração de elementos virtuais no } \\
\text { ambiente real, por meio de uma câmera e e } \\
\text { com o uso de sensores de movimento. }\end{array}$ & $\begin{array}{l}\text { Permite o aumento de trabalhos a distância e } \\
\text { a simulação de tarefas. }\end{array}$ \\
\hline $\begin{array}{l}\text { Se refere a aplicabilidade de testar e } \\
\text { aprimorar os produtos na etapa de } \\
\text { concepção, simulando toda a cadeia de } \\
\text { criação. }\end{array}$ & $\begin{array}{l}\text { Evita o desperdício, reduz o tempo e os } \\
\text { prejuízos. }\end{array}$ \\
\hline
\end{tabular}

Os pilares apresentados no Quadro 1 apontam que a indústria 4.0 tem o potencial de impactar em todos os âmbitos da vida individual e coletiva. Essa ideia fica evidenciada em Lavagnoli (2018), que afirma que a sociedade, em vários setores, tem se alterado não só pelas transformações trazidas pela nova era industrial, mas também pelas novas maneiras de se utilizar a tecnologia, sendo que, dentre os setores, destaca-se o da educação e o interesse em descobrir como esses pilares da indústria 4.0 podem ser aplicados em favor dela.

\section{METODOLOGIA}

Sobre o caminho metodológico, realizou-se, no primeiro semestre de 2021, uma pesquisa básica, de abordagem qualitativa. De acordo com o objetivo traçado, o tipo de pesquisa foi a descritiva. Em relação aos procedimentos técnicos, escolheu-se a pesquisa bibliográfica.

As principais referências utilizadas para a realização desta pesquisa foram artigos, livros e publicações em Fóruns. Assim, foram considerados os estudos de vários pesquisadores de diferentes áreas como, por exemplo, os estudos que tratam da sociedade na era digital, Castells (1999), Lévy (2009), Tapscott (2010) e Schmidt e Cohen (2013); estudos sobre os modelos educacionais: Franco (2014), Silva e Camargo (2015), Lengel (2017) e Lavagnoli (2018); estudos sobre a cultura digital e as novas práticas pedagógicas: Moran (2004), Bacich et al. (2015), Lorenzoni (2016) e Andrade (2018); estudos sobre a digitalização nos processos de trabalho e a $4^{\text {a }}$ revolução industrial: Antonio et al. (2018), World Economic Forum (2018, 2020), World Bank Group (2019) e o Forum Econômico Mundial ( 2019); e estudos sobre os pilares da indústria 4.0: Boston Consulting Group (2017) e Lavagnoli (2018).

A escolha desses autores se deve à relevância dos estudos desenvolvidos, seja por meio de livros ou artigos, e também porque são autores que se dedicam a pensar sobre os modelos educacionais e sua relação/alinhamento com as mudanças na sociedade, com as relações sociais e educacionais mediadas pelas tecnologias.

\section{RESULTADOS E ANÁLISES}

Neste item, será apresentado como os nove pilares da indústria 4.0 podem ser aplicados na educação, bem como suas possibilidades. Para tal, verificou-se, nesta pesquisa, que todo o potencial 
das tecnologias presentes na indústria 4.0 pode favorecer a educação, contribuindo com o processo de ensino-aprendizagem (LAVAGNOLI, 2018). No Quadro 2, estão apresentados como cada pilar da indústria 4.0 pode ser aplicado na educação, seja diretamente como prática pedagógica ou, indiretamente, na gestão escolar.

Quadro 2 - Aplicação dos pilares da indústria 4.0 na educação

\begin{tabular}{|c|c|c|}
\hline \multirow{2}{*}{ Pilares } & \multicolumn{2}{|l|}{ Exemplo de Aplicações } \\
\hline & $\begin{array}{l}\text { De uso como ferramenta de apoio na gestão } \\
\text { escolar }\end{array}$ & De uso diretamente nas práticas pedagógicas \\
\hline $\begin{array}{l}\text { Big Data } \\
\text { e Data Analytics }\end{array}$ & $\begin{array}{l}\text { *Analise de dados para acompanhar e avaliar } \\
\text { o desenvolvimento dos alunos, como no } \\
\text { AVA. Na medida em que um aluno estuda } \\
\text { e completa exercícios, o sistema identifica } \\
\text { os assuntos que ele domina, as lacunas na } \\
\text { aprendizagem e sugere roteiros de estudo que } \\
\text { se adequem às suas dificuldades e tempo que } \\
\text { dedica à matéria, podendo traçar um perfil dos } \\
\text { alunos, compreender sua trajetória, sugerir } \\
\text { caminhos para a melhoria e de sua prática } \\
\text { pedagógica (LORENZONI, 2016). }\end{array}$ & $\begin{array}{l}\text { *Propicia a aplicação das metodologias ativas, } \\
\text { aprendizagem baseada em problemas, que acessem } \\
\text { as informações disponíveis na internet para resolver } \\
\text { problemas da vida real. Um exemplo de prática seria } \\
\text { dividir a turma em grupos ou equipes e cada um } \\
\text { deveria levantar o maior número de dados sobre um } \\
\text { determinado assunto em seus vários períodos da } \\
\text { história. A exemplo da história das pandemias, cada } \\
\text { grupo ficaria responsável por levantar os dados de } \\
\text { um tipo de pandemia ou de pandemias de um período } \\
\text { e, a outra equipe, com outro período. }\end{array}$ \\
\hline Cibersegurança & $\begin{array}{l}\text { *Proteção dos dados e sistemas, no caso, os } \\
\text { AVA, das ameaças cibernéticas, por meio de } \\
\text { softwares específicos para tal. }\end{array}$ & $\begin{array}{l}\text { *Possibilita o trabalho, com os alunos e professores, } \\
\text { sobre a conscientização sobre o uso de softwares } \\
\text { que podem conter vírus e boas práticas de } \\
\text { comportamento digital. }\end{array}$ \\
\hline $\begin{array}{l}\text { Computação em } \\
\text { Nuvem }\end{array}$ & $\begin{array}{l}\text { *Dispensa de instalação de softwares } \\
\text { ou sistemas no computador, diminuindo } \\
\text { a necessidade de altos investimentos } \\
\text { financeiros em armazenagem de dados. }\end{array}$ & $\begin{array}{l}\text { *Permite o uso do OneNote, que é um caderno } \\
\text { de anotação em nuvem da Microsoft, conferindo } \\
\text { autonomia aos alunos, pois eles podem ter o acesso } \\
\text { completo às matérias das aulas a qualquer hora e } \\
\text { lugar. Essa tecnologia permite o compartilhamento de } \\
\text { mídias. O aluno pode inserir conteúdos em planilhas, } \\
\text { gráficos e imagens e que podem ser editados no } \\
\text { próprio bloco de anotações. Também pode-se editar } \\
\text { as informações em grupo em tempo real, integrando } \\
\text { tarefas e anotações com o serviço de correio de } \\
\text { mensagens (MORAIS, 2019). } \\
\text { *Permite o uso do google drive, da empresa Google Corp } \\
\text { e OneDrive da Microsoft, como ambientes colaborativos } \\
\text { que permitem aos alunos compartilhamento de } \\
\text { documentos, planilhas, ferramentas de apresentação, } \\
\text { ambientes de espaços colaborativos em mural, como o } \\
\text { Padlet. }\end{array}$ \\
\hline $\begin{array}{l}\text { Integração de } \\
\text { Sistemas }\end{array}$ & $\begin{array}{l}\text { *Implementação de um sistema de gestão } \\
\text { escolar, a partir da criação de uma } \\
\text { coordenação sistemática entre os diversos } \\
\text { setores e atores que constituem as instituições } \\
\text { de ensino, por meio de uma rede de dados. } \\
\text { Os elementos de integração de sistemas são: } \\
\text { as matrículas, as informações acadêmicas, a } \\
\text { captação de alunos, a comunicação com os } \\
\text { pais e com os alunos (especificamente sobre } \\
\text { o uso de recursos tecnológicos, para que eles } \\
\text { tenham acesso as suas notas e materiais } \\
\text { didáticos) (FERREIRA, 2020). }\end{array}$ & $\begin{array}{l}\text { *Oportuniza o uso de AVA que possibilita a integração } \\
\text { dos sistemas como recursos de inclusão de vídeos de } \\
\text { Youtube, acesso direto a ferramentas colaborativas, } \\
\text { como Jamboard; o recurso de hyperlink dentro de } \\
\text { slides de apresentações, de documentos de textos. }\end{array}$ \\
\hline
\end{tabular}




\begin{tabular}{|c|c|c|}
\hline $\begin{array}{l}\text { Internet das } \\
\text { Coisas }\end{array}$ & $\begin{array}{l}\text { *Rastreio de objetos ou pessoas, como } \\
\text { a frequência do aluno, a localização de } \\
\text { professores e o rastreio de objetos como } \\
\text { laptops, livros, ou objetos do patrimônio } \\
\text { institucional. Também é possível, com o uso } \\
\text { de dispositivos da neurociência, identificar } \\
\text { os aspectos afetivos do aluno, auxiliando o } \\
\text { professor a adequar o conteúdo, monitorando } \\
\text { a motivação e o engajamento dos alunos } \\
\text { em uma atividade, permitindo que estilos } \\
\text { diferenciados de aprendizado sejam aplicados } \\
\text { (SILVA et al., 2017). }\end{array}$ & $\begin{array}{l}\text { *Possibilita a aplicação da metodologia ativa sala } \\
\text { de aula invertida (flipped classroom), na qual aulas } \\
\text { podem ser assistidas diversas vezes e usadas como } \\
\text { base para projetos práticos relacionados a uma lição } \\
\text { específica. As aulas presenciais são transformadas } \\
\text { em sessões de um projeto e o foco do aprendizado } \\
\text { está na realização desse projeto e não em assistir } \\
\text { aulas expositivas (SILVA et al., 2017). } \\
\text { * Um exemplo seria uma aula com o tema referente } \\
\text { a características da fotossíntese, que poderia ser } \\
\text { ministrada apresentando-se, além do conhecimento } \\
\text { teórico, dados reais adquiridos por sensores } \\
\text { espalhados em uma determinada floresta. Logo, os } \\
\text { dados empíricos reforçariam os conceitos dados em } \\
\text { sala de aula (SILVA et al., } 2017, \text { p. 1262). }\end{array}$ \\
\hline $\begin{array}{l}\text { Manufatura } \\
\text { aditiva }\end{array}$ & $\begin{array}{l}\text { *Fabricação de ferramentas pedagógicas que } \\
\text { serão utilizadas como apoio ao professor, de } \\
\text { diferentes materiais e formas. }\end{array}$ & $\begin{array}{l}\text { *Permite que os alunos coloquem em prática as } \\
\text { ideias que tiveram para resolver um problema dado } \\
\text { pelo professor. Eles podem construir protótipos e } \\
\text { recriar obras de artes, graças às impressoras 3D e } \\
\text { aos softwares para desenho 3D, como o TinkerCAD. } \\
\text { * Nas aulas teóricas e expositivas, os professores } \\
\text { podem mostrar as estruturas ósseas, próteses, } \\
\text { motores, dentre vários outros exemplos, de acordo } \\
\text { com o conteúdo de suas disciplinas, como criar } \\
\text { artefatos como células, vírus, órgãos e outros em 3D } \\
\text { para as aulas de ciências e biologia, ou ainda, para } \\
\text { geografia ou história, com a recriação de mapas, } \\
\text { lugares ou personagens históricos. } \\
\text { *Aplicação das metodologias ativas, como a } \\
\text { aprendizagem baseadas em projetos, design thinking } \\
\text { e atividades maker. }\end{array}$ \\
\hline $\begin{array}{l}\text { Realidade } \\
\text { aumentada }\end{array}$ & & $\begin{array}{l}\text { * Possibilita o uso de jogos com base na Realidade } \\
\text { aumentada para o ensino de um conteúdo, envolvendo } \\
\text { a resolução de um problema em forma de desafio. } \\
\text { *Nas aulas de biologia, os alunos podem ver o "corpo } \\
\text { humano por uma nova perspectiva, uma camada por } \\
\text { vez. As imagens tridimensionais de alta qualidade } \\
\text { facilitam a compreensão da anatomia e da fisiologia do } \\
\text { corpo humano, possibilitando aos alunos gerarem um } \\
\text { conhecimento mais profundo" (LOPES et al., 2019, p. 22). }\end{array}$ \\
\hline $\begin{array}{l}\text { Robôs } \\
\text { autônomos }\end{array}$ & $\begin{array}{l}\text { *Integração de AVA, usado como simulador, } \\
\text { virtualização de sistema acadêmico. Também } \\
\text { pode-se fazer a análise de dados complexos, } \\
\text { realizando cálculo de festa de alunos e da } \\
\text { empresa, incluindo a parte de mídia social. }\end{array}$ & $\begin{array}{l}\text { *Propicia a construção de robôs autônomos } \\
\text { seguidores de linha, capazes de executar um objetivo } \\
\text { (como seguir uma linha branca em uma pista preta, } \\
\text { por exemplo), sendo programados para passar por } \\
\text { desafios sem a necessidade do contato humano. } \\
\text { Para tal, os alunos precisam colocar em prática vários } \\
\text { conhecimentos, tais como mecânica, eletrônica, } \\
\text { lógica e programação, dentre outros. Os alunos têm } \\
\text { a oportunidade de levantar e testar hipóteses para } \\
\text { a resolução de problema. Além disso, os alunos } \\
\text { aprendem a trabalham em equipe e despertam o } \\
\text { interesse pela robótica. }\end{array}$ \\
\hline Simulações & & $\begin{array}{l}\text { *Oportuniza o uso de softwares que foram } \\
\text { programados para fazerem simulações virtuais de } \\
\text { aulas práticas, como o Balanceamento de Equações } \\
\text { Químicas. Esse simulador engloba os conteúdos } \\
\text { de uma disciplina de Química. Outro exemplo de } \\
\text { simuladores na educação são os pacientes virtuais } \\
\text { utilizados nas aulas de medicina. } \\
\text { * O site PHET (https://phet.colorado.edu/pt_BR/) } \\
\text { apresenta várias possiblidades de simuladores } \\
\text { virtuais para as áreas de Física, Matemática, Química } \\
\text { e Biologia. }\end{array}$ \\
\hline
\end{tabular}

Fonte: Dados de pesquisa (2021) 
Vale salientar que, nesta pesquisa, gestão escolar é compreendida a partir de Lück (2009, p. 23), como uma área que "destina-se a realizar o planejamento, a organização, a liderança, a orientação, a mediação, a coordenação" das ações realizadas no contexto escolar, englobando o trabalho desenvolvido pela direção, coordenação pedagógica, secretaria e conselhos estabelecidos, com participação de pais, professores e alunos.

Embora os nove pilares apresentados no Quadro 2 tenham sido desenhados para aplicação na indústria 4.0, a partir dos artigos utilizados no corpus desta pesquisa, pode-se afirmar que eles já estão chegando nas escolas. Dessa maneira, com a educação absorvendo essas novas tecnologias, é possível denominá-la Educação 4.0, na qual o modelo tradicional de ensino está, aos poucos, sendo modificado: a sala de aula vai se tornando digital e mais colaborativa como, por exemplo, com o uso de ferramentas como o Jamboard e o Padlet, e com atividades que permitem a interação entre alunos e professores.

É importante ressaltar que as escolas devem atuar de forma adaptativa, entendendo a necessidade de cada aluno e oferecendo novas formas de conteúdo, alinhados às características de cada indivíduo. A análise do ritmo de cada aluno, as dificuldades e as individualidades que são coletadas, em tempo real ou não, ajudam na construção de um caminho, proposto pela prática pedagógica, de forma a atuar tanto na elaboração quanto no ensino, procurando garantir que todos atinjam o objetivo proposto, mas cada um ao seu modo (BOSTON CONSULTING GROUP, 2019).

Seguindo nessa mesma linha de pensamento, o pilar Big Data e Data Analytics é um exemplo de como o professor pode acompanhar o caminho de aprendizagem de seus alunos e guiá-los por trajetórias que os conduziriam para uma aprendizagem mais motivadora e até personalizada (ANDRADE, 2018; LORENZONI, 2016).

Dentre essas práticas pedagógicas, destaca-se, neste estudo, que os pilares da indústria 4.0 permitem a aplicação das metodologias ativas, as quais colocam o aluno no centro do processo de ensino-aprendizagem. Eles aprendem fazendo e também mudam o papel dos professores, que passam de detentores do conhecimento para mediadores desse processo (BACICH et al., 2015).

Outro achado na pesquisa foi perceber que a automatização e os AVA já são realidades na educação e permitem que a escola proporcione para os alunos ambientes e práticas pedagógicas inovadoras, possibilitando resoluções de problemas e desenvolvimento de projetos voltados para a sociedade na era da indústria 4.0. Destarte, vai se percebendo que a escola vem implementando uma nova cultura, a cultura digital, voltada para um modelo de ensino que usa a tecnologia para estabelecer novas configurações de aprendizagem (SILVA; CAMARGO, 2015).

Entretanto, os autores lembram que, para a cultura digital ser realmente estabelecida, será necessário o engajamento dos professores e de toda equipe da escola com o novo modelo de ensino, de forma a atingir o interesse dos alunos e, para isso, é necessário que os professores se sintam estimulados a saírem da zona de conforto. Para tal, é preciso que a escola crie redes de apoio, preparação de sua equipe, implementação da infraestrutura e disponibilidade tecnológica, além de um projeto pedagógico compatível com a era digital.

Por último, vale ressaltar que a gestão escolar também tem incorporado as tecnologias digitais no seu cotidiano administrativo. No Quadro 2, estão apresentados alguns exemplos dessa incorporação como, por exemplo, o pilar Internet das coisas. Esse pilar é responsável pela conexão digital de toda a escola, formando uma rede de equipamentos para reunir e transmitir dados. Assim, a escola caminha para uma realidade de hiperconectividade, a qual, para Rocha et al. (2020), é uma tendência (ROCHA et al., 2020). 
Durante esta pesquisa, não foram verificadas publicações que remetam à presença de aplicação dos pilares Realidade Aumentada e Simulações na gestão escolar, o que não significa que elas não estejam acontecendo. Entretanto, esses dois pilares já estão inseridos nas práticas pedagógicas, como os exemplos descritos no Quadro 2.

\section{CONSIDERAÇÕES FINAIS}

Ao final desta pesquisa, pode-se responder à questão norteadora que deu origem a ela: é possível utilizar os avanços tecnológicos da indústria 4.0 no contexto escolar para efetivar o modelo educacional 4.0? E a resposta é sim. Os resultados revelaram que os pilares da indústria 4.0 estabelecidos pelo Boston Consulting Group podem ser aplicados à educação, seja diretamente nas práticas pedagógicas, seja indiretamente, como ferramenta de apoio na gestão escolar.

Sobre a aplicação dos pilares da indústria 4.0 na educação, nas práticas pedagógicas, verificou-se que eles têm favorecido o uso das metodologias ativas, destacando-se, nesta pesquisa a aprendizagem baseada em projetos, a sala de aula invertida, o design thinking e atividades maker (faça você mesmo). Dessa forma, consegue-se um maior engajamento dos alunos no aprendizado, colocando-os como protagonistas no processo de ensino-aprendizagem e os professores como mediadores desse processo.

A pesquisa também mostrou que o uso dos pilares da indústria 4.0 na educação possibilita, por meio dos AVA, a integração dos sistemas como recursos de inclusão de vídeos de Youtube, acesso direto a ferramentas colaborativas, como Jamboard e o Padlet, além do recurso de hyperlink dentro de slides de apresentações ou de documentos de textos. Logo, a aprendizagem se torna mais colaborativa.

O modelo tradicional de ensinar e aprender tem-se modificado ao longo dos anos e, atualmente, pode-se dizer que o modelo de educação atual é o 4.0, o qual não se resume apenas em equipar as instituições de ensino. Embora, o uso das tecnologias digitais como ferramenta na rotina das escolas seja fundamental, por si só, não acarretará grandes transformações (SILVA; CAMARGO, 2015). Também se faz necessário ressignificar as práticas pedagógicas, principalmente pela adoção de metodologias ativas, como acreditam Bacich et al. (2015,) para que tenham um significado para os alunos que vivem em uma sociedade digital, que requerem, desses novos conhecimentos, atitudes e habilidades.

Por conseguinte, entende-se que a educação 4.0 já está chegando às escolas, como apresentado no Quadro 2. Todavia, não se pode afirmar que já seja realidade em todas as escolas, uma vez que não foi objetivo deste artigo fazer essa investigação e, sim, relatar suas possibilidades.

\section{REFERÊNCIAS}

ANDRADE, Karen. 0 desafio da Educação 4.0 nas escolas. Disponível em: https://canaltech.com.br/ mercado/o-desafio-da-educacao-40-nas-escolas-109734/. Acesso em: 19 dez. 2020.

ANTONIO, Daniel Soares; AMARANTE, Mayara dos Santos; GERIBELLO, Renato Sabino; NASCIMENTO, Gabriela Afonso do; ALMEIDA, Robson Rodrigues de; PAULA, Rafael Mendes de, SOUZA, Maria Luiza Rinaldi de; PLATERO, Karine de Brito. indústria 4.0 e seus impactos na sociedade. Pesquisa e Ação, São Paulo, v.4, n.3, nov. 2018. Disponível em: https://revistas.brazcubas.br/index.php/pesquisa/article/ view/498. Acesso em: 17 jan. 2021. 
BACICH, Lilian; TANZI NETO, Adolfo; TREVISANI, Fernando de Mello. (Org.). Ensino Híbrido: Personalização e Tecnologia na Educação. Porto Alegre: Penso editora, 2015.

BOSTON CONSULTING GROUP. Industry 4.0: The Future of Productivity and Growth in Manufacturing Industries. 2015. Disponível em: https://www.bcg.com/pt-br/publications/2015/engineered_products_ project_business_industry_4_future_productivity_growth_manufacturing_industries/. Acesso em: 24 jan. 2021.

BOSTON CONSULTING GROUP. Gaining Robotics Advantage. 2017. Disponível em: https://www.bcg.com/ en-br/publications/2017/strategy-technology-digital-gaining-robotics-advantage/. Acesso em: 24 jan. 2021.

CARVALHO, Núbia Gabriela Pereira. Trabalho Humano na Industria 4.0: Percepções brasileiras e alemãs dos setores acadêmico e empresarial a respeito do trabalho de pessoas no novo modelo industrial. 2019. 260f. Dissertação (Mestrado em Engenharia de Produção) - Escola de Engenharia da Universidade de São Paulo, São Carlos, 2019.

CASTELLS, Manuel. A sociedade em rede. São Paulo: Paz e Terra, 1999.

FRANCO, Carolina M.S.S. Educação 1.0, 2.0, 3.0. 2014. Disponível em: https://pt.slideshare.net/cfranco30/ educao-10-20-30. Acesso em: 20 dez. 2020.

FERREIRA, Felipe. Saiba tudo sobre integração de sistemas nas escolas. 2020. Disponível em: http:// www.proesc.com/blog/tudo-sobre-integracao-de-sistemas-nas-escolas/. Acesso em: 18 jan. 2020.

INSTITUTO CLAYTON CHRISTENSEN. Blended learning Universe. 2018. Disponível em: http://www. blendedlearning.org. Acesso em: 07 fev. 2021.

LAVAGNOLI. Silvia. Indústria 4.0 - Evolução ou Revolução? 2018. Disponível em: https://opencadd.com. br/9-pilares-da-industria-4-0/. Acesso em: 19 dez. 2020.

LENGEL, J. G. A evolução da educação: 1-2-3. In: Carvalho, M. T. (Org.). Educação 3.0: novas perspectivas para o ensino. São Leopoldo, RS: Unisinos, 2017.

LÉVY, Pierre. Cibercultura. São Paulo: Editora 34, 2009.

LOPES, Luana Monique Delgado; VIDOTTO, Kajiana Nuernberg Sartor; POZZEBON, Eliane; FERENHOF, Helio Aisenberg. Inovações educacionais com o uso da realidade aumentada: uma revisão sistemática. Educação em Revista, Belo Horizonte, v.35, p. 1-33, 2019.

LORENZONI, Marcela. Big data na educação: o que é e como usar? - Infográfico. 2016. Disponível em: https://site.geekie.com.br/blog/big-data-na-educacao/. Acesso em: 18 jan. 2010.

LÜCK, HELOÍSA. Dimensões de gestão escolar e suas competências. Curitiba: Editora Positivo, 2009.

MORAIS, Lenildo. Computação na Nuvem: Quais as Vantagens para a Educação? 2019. Disponível em: https://www.channel360.com.br/computacao-na-nuvem-quais-as-vantagens-para-a-educacao/. Acesso em: 18 jan. 2021.

MORAN, José Manuel. A educação que desejamos: novos desafios e como chegar lá. São Paulo: Papirus, 2007. 
ROCHA, Bruno Augusto Barros; LIMA, Fernando Rister de Sousa; WALDMAN, Ricardo Libel. Mudanças no papel do indivíduo pós-revolução industrial e o mercado de trabalho na sociedade da informação. Revista Pensamento Jurídico, São Paulo, v. 14, n.1, jan./jul. 2020. Disponível em: https://fadisp.com.br/ revista/ojs/index.php/pensamentojuridico/article/view/202. Acesso em: 17 jan. 2021

SCHMIDT, Eric; COHEN, Jared. A nova era digital: como será o futuro das pessoas, das nações e dos negócios. Rio de Janeiro: Intrínseca, 2013.

SILVA, Rafael de Amorim; NOVA, João Gabriel G.V.; VASCONCELOS, Rubem F.S.; CALADO, Ivo A.A.R.; BRANCO, Kalinka R.L.J.C.; BRAGA, Rosana T.V. Aplicando Internet das Coisas na Educação: Tecnologia, Cenários e Projeções. 2017. Anais dos Workshops do VI Congresso Brasileiro de Informática na Educação (WCBIE 2017). Disponível em: file:///C:/Users/User/AppData/Local/Temp/7514-9502-1-PB-1.pdf. Acesso em: 18 jan. 2021.

SILVA, Rodrigo Abrantes da; CAMARGO, Ailton Luiz. A cultura escolar na era digital. In: BACICH, Lilian; NETO, Adolfo Tanzi; TREVISANI, Fernando de Mello. (Orgs.). Ensino híbrido: personalização e tecnologia na educação. Porto Alegre: Penso, 2015.

TAPSCOTT, Don. A hora da Geração Digital. Rio de Janeiro: Agir, 2010.

WORLD BANK GROUP. The changing nature of work: world development report. 2019. Disponível em: https://www.oitcinterfor.org/sites/default/files/file_publicacion/2019WDRDraftReport.pdf. Acesso em: 17 jan. 2021.

WORLD ECONOMIC FORUM. The Future of Jobs Report: Centre for The new Economy and Society. 2018. Disponível em: https://www.abet-trabalho.org.br/the-future-of-jobs-report-2018-forum-economico-mundial. Acesso em: 27 jul. 2019.

WORLD ECONOMIC FORUM. The Future of Jobs Report. 2020. Disponível em: http://www3.weforum. org/docs/WEF_Future_of_Jobs_2020.pdf. Acesso em: 17 jan. 2021. 